\title{
Enhancing Methane Conversion by Modification of Zn States in Co-Reaction of MTA
}

\author{
Yue Yu ${ }^{\dagger}$, , Zhixiang $\mathrm{Xi}^{\dagger}$, Bingjie Zhou, Binbo Jiang *, Zuwei Liao, Yao Yang, Jingdai Wang, Zhengliang Huang, \\ Jingyuan Sun and Yongrong Yang \\ Zhejiang Provincial Key Laboratory of Advanced Chemical Engineering Manufacture Technology, \\ College of Chemical and Biological Engineering, Zhejiang University, Hangzhou 310027, China; \\ yuyue98983@gmail.com (Y.Y.); xizx@zju.edu.cn (Z.X.); zbj_lily@163.com (B.Z.); liaozw@zju.edu.cn (Z.L.); \\ yao_yang@zju.edu.cn (Y.Y.); wangjd@zju.edu.cn (J.W.); huangzhengl@zju.edu.cn (Z.H.); sunjy@zju.edu.cn (J.S.); \\ yangyr@zju.edu.cn (Y.Y.) \\ * Correspondence: jiangbb@zju.edu.cn \\ + These authors contributed equally to this work.
}

Citation: Yu, Y.; Xi, Z.; Zhou, B.; Jiang, B.; Liao, Z.; Yang, Y.; Wang, J.; Huang, Z.; Sun, J.; Yang, Y. Enhancing Methane Conversion by Modification of $\mathrm{Zn}$ States in Co-Reaction of MTA. Catalysts 2021, 11, 1540. https:// doi.org/10.3390/catal11121540

Academic Editor: Enrique

García-Bordejé

Received: 24 November 2021 Accepted: 14 December 2021 Published: 17 December 2021

Publisher's Note: MDPI stays neutral with regard to jurisdictional claims in published maps and institutional affiliations.

Copyright: (c) 2021 by the authors. Licensee MDPI, Basel, Switzerland. This article is an open access article distributed under the terms and conditions of the Creative Commons Attribution (CC BY) license (https:// creativecommons.org/licenses/by/ $4.0 /)$.
Abstract: Limited by harsh reaction conditions, the activation and utilization of methane were regarded as holy grail reaction. Co-reaction with methanol, successfully realizing mild conversion below $450{ }^{\circ} \mathrm{C}$, provides practical strategies for methane conversion on metal-loaded ZSM- 5 zeolites, especially for highly efficient $\mathrm{Zn}$ loaded ones. However, $\mathrm{Zn}$ species, regarded as active acid sites on the zeolite, have not been sufficiently studied. In this paper, Zn-loaded ZSM-5 zeolite was prepared, and $\mathrm{Zn}$ was modified by capacity, loading strategy, and treating atmosphere. Apparent methane conversion achieves $15.3 \%$ for $1.0 \mathrm{Zn} / \mathrm{Z}-\mathrm{H}_{2}(16.8 \%$ as calculated net conversion) with a significantly reduced loading of $1.0 \mathrm{wt} . \%$ against deactivation, which is among the best within related zeolite materials. Besides, compared to the MTA reaction, the addition of methane promotes the high-valued aromatic production from $49.4 \%$ to $54.8 \%$, and inhibits the $\mathrm{C} 10+$ production from $7.8 \%$ to $3.6 \%$. Notably, $\mathrm{Zn}^{2+}$ is found to be another active site different from the reported $\mathrm{ZnOH}^{+}$. Medium strong acid sites are proved to be beneficial for methane activation. This work provides suggestions for the modification of the $\mathrm{Zn}$ active site, in order to prepare highly efficient catalysts for methane activation and BTX production in co-reaction with methanol.

Keywords: methane; co-reaction; MTA; aromatics; Zn

\section{Introduction}

Methane is a vital fossil energy, largely present in natural gas, shale gas, combustible ice and other resources. Its tetrahedral symmetry and high $\mathrm{C}-\mathrm{H}$ bond energy, make the activation more challenging [1-3]. Moreover, the products and intermediates formed by methane conversion, such as methanol and formic acid, show higher activities than methane and are easily over-oxidized to carbon dioxide [1-3]. Generally, methane is utilized through indirect methods, such as the reformation into syngas combined with FischerTropsch synthesis [1-3]. However, the indirect methane conversion route causes massive energy consumption, together with high equipment costs [1]. Therefore, it is essential for developing direct methane conversion strategies for producing high value-added chemicals or fuels in mild conditions

Co-reaction, as a method of direct conversion of methane, realizes mild and highefficiency conversion of methane at temperatures below $600{ }^{\circ} \mathrm{C}$, far lower than a methane reformation process up to above $1000^{\circ} \mathrm{C}$ [3]. Currently, various co-feed materials have been proved to be effective in mitigating the methane conversion temperature, including C3 C6 hydrocarbons, methanol, ethanol, acetic acid, etc. [4-6]. Methanol, as a coal-based C1 resource, its co-reaction with methane can effectively promote the methane conversion under mild conditions, but also increase the selectivity of high value-added aromatics in the products (Scheme 1) [7,8]. Sachchit et al. [7] prepared 2\%Ga-5\%Mo/HZSM-5, which presented 
maximum methane conversion of $15.5 \%$ and aromatic selectivity of $88.7 \%$. Liu et al. [8] reported that methane conversion, coupled with methanol methylation reaction, reached methane conversion of $26.4 \%$ and BTX selectivity of larger than $90 \%$ at $700{ }^{\circ} \mathrm{C}$ on $6 \%$ Mo/ZSM-5. In methane conversion with co-feeding of methanol to aromatics (MTA) reaction, the strong exothermic effect of the MTA reaction provides a favorable condition for the activation of methane, which is conducive to the efficient use of energy and realizes the gentle activation of methane below $500{ }^{\circ} \mathrm{C}[9,10]$. At the same time, the activated methane acts as a carbon source for the BTX product, realizing the efficient and direct utilization of methane.

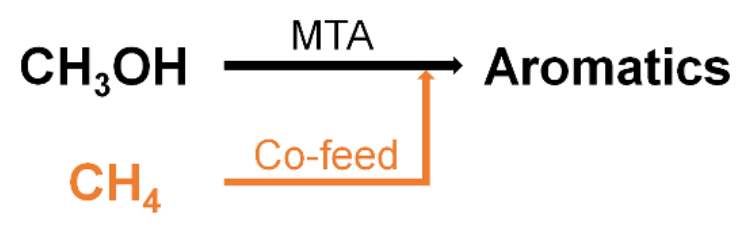

\section{Catalyzed by Zn modified ZSM-5}

Scheme 1. Co-reaction and methanol to aromatics (MTA) reaction studied in this work.

Metal sites play key role in both of methane dehydrogenation aromatization (MDA), and MTA reaction, which are two parts of the co-reaction [11,12]. The introduction of metals can activate the $\mathrm{C}-\mathrm{H}$ bond of methane [11] and promote the dehydrogenation reaction path in the MTA reaction [12]. Metal sites are regarded as active sites, which also change the acidities of zeolite catalysts. Therefore, it is necessary for deep investigation of metal sites.

$\mathrm{Zn}$, which is reported to show high efficiency in MTA reactions, also shows excellent methane conversion ability in co-reactions [13]. A previous report prepared impregnated ZSM-5, and Zn modification shows the highest activity among Ni, Mo, La, Ga, Fe and Co [14]. However, only a few studies focused on $\mathrm{Zn}$ sites on the catalyst [15-17], whose state has important influence. Abdelsayed et al. $[15,17]$ proposed that $\mathrm{ZnOH}^{+}$and $\mathrm{ZnO}$ are two existing forms on HZSM-5. $\mathrm{ZnOH}^{+}$dominated the ZSM- 5 catalyst at low content of $1-2 \mathrm{wt} . \%$ and was beneficial for methane activation in MDA. Besides, Niu et al. [18] found that the relative proportion of $\mathrm{ZnOH}^{+}$was linearly positively correlated with the selectivity of aromatics on Zn modified ZSM- 5 catalysts in MTA reactions. Further research is still needed against the active $\mathrm{Zn}$ on the catalyst.

Zn species transform variously in different conditions. Previous reports $[10,19]$ showed that $\mathrm{ZnOH}^{+}$transformed to bridged amorphous $\mathrm{Zn}-\mathrm{O}-\mathrm{Zn}$ species with the increase of Zn content on ZSM-5 zeolite, which indicates that oxide Zn species exist in bulk size and dispersive form. Recent study [20] found that $\mathrm{ZnOH}^{+}$on ZSM-5 can be converted to $\mathrm{Zn}^{2+}$ after hydrogen treatment at $300{ }^{\circ} \mathrm{C}$, which showed higher activity in the aromatization of ethylene. However, few research focus on varying the $\mathrm{Zn}$-center could be found on methane activation in co-reaction with MTA.

Moreover, the reported metal capacities of the catalysts used in the co-reaction of methane and methanol, are relatively high, reaching more than $3 \mathrm{wt} . \%$. On the one hand, high metal loading is likely to cause blockage of the pores and active sites on catalysts to affect the diffusion or interaction of reactants or products, especially for aromatic products. On the other hand, harsh reaction conditions lead to metal sintering, resulting in irreversible deactivation. Besides, it is a competitive relationship in the amount between the strong acid sites, which activate methanol, and medium strong acid sites generated by metal and Brönsted acid sites, which activate methane. Therefore, the amount of $\mathrm{Zn}$ content should be optimized, and the development of low metal loading catalysts is important for improving the catalyst stability and lengthening the catalyst-serving lifetime.

In this paper, Zn-modified ZSM- 5 zeolites were prepared for methane conversion in coreaction with methanol. Zn content, loading strategies and treating atmosphere were optimized. Co-reaction catalyst with high methane activation was obtained. Ionic and oxidized 
$\mathrm{Zn}$ species were discussed in activation of methane. The results provide theoretical guidance for the development of high-performance catalysts suitable for methane utilization.

\section{Results and Discussions}

2.1. ZSM-5 Catalysts with Different Zn Content for Methane Conversion in Co-Reaction of Methanol to Aromatics (MTA) Reaction

\subsubsection{Characterization}

Zn-impregnated ZSM-5 zeolites were prepared with 1.0, 2.0 and $3.0 \mathrm{wt} . \%$ loadings. Figure 1a shows the XRD patterns of ZSM- 5 samples and MFI simulated one at the $2 \theta$ range of $5-40^{\circ}$. It can be seen that the experimental peaks are in correspondence with the simulated ones, which indicates pure phases and the impregnation operations do not destroy the framework topology of MFI. Zn species in zeolites are focused on in XRD patterns at $2 \theta$ range of $30-40^{\circ}$ of ZSM-5 samples and powder $\mathrm{ZnO}$. As shown in Figure $1 \mathrm{~b}$, $3.0 \mathrm{Zn} / \mathrm{Z}$ show weak peaks at $31.8^{\circ}, 34.5^{\circ}$ and $36.3^{\circ}$, which is evidence of the existence of $\mathrm{ZnO}$. However, no such peaks can be found in $1.0 \mathrm{Zn} / \mathrm{Z}$ and $2.0 \mathrm{Zn} / \mathrm{Z}$, which could be attributed to the highly dispersion of Zn species. SEM images in Supplementary Materials Figure S1 show polyhedral morphology of HZSM- 5 with diameter of 1-5 $\mu \mathrm{m}$. After Zn modification, crystals maintain morphology and slightly break into pieces. Contents of Zn on ZSM-5 samples are analyzed by inductively coupled plasma optical emission spectrometry (ICP-OES). As shown in Table $1,1.0 \mathrm{Zn} / \mathrm{Z}, 2.0 \mathrm{Zn} / \mathrm{Z}$ and $3.0 \mathrm{Zn} / \mathrm{Z}$ shows $\mathrm{Zn}$ content of 0.99, 1.70 and 2.93 wt.\%. EDS images shown in Figure S2 indicates uniform distributions of $\mathrm{Zn}$ species.
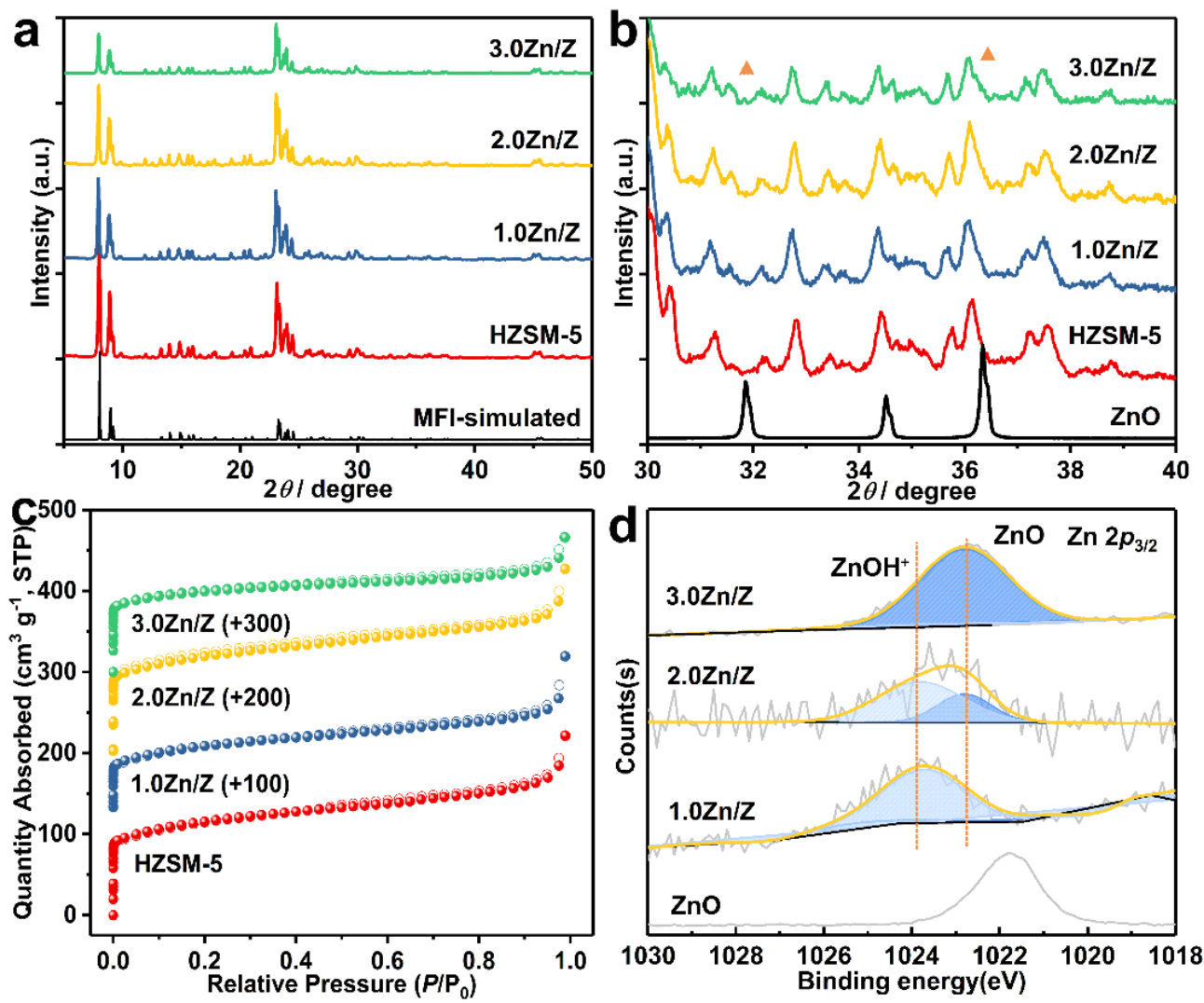

Figure 1. $\mathrm{X}$-ray diffraction (XRD) patterns in the range of $5-50^{\circ}$ of ZSM-5 samples and MFI simulated one (a), and in range of $30-40^{\circ}$ of ZSM-5 samples and $\mathrm{ZnO}(\mathbf{b}) ; \mathrm{N}_{2}$ adsorption-desorption isotherms at $77 \mathrm{~K}$ of HZSM-5 and Zn-modified ZSM- 5 zeolites (c); fittings of Zn 2 $p_{3 / 2}$ peaks in X-ray photoelectron spectroscopy (XPS) spectra of ZnO and Zn-modified ZSM-5 samples (d). 
Table 1. Zn content, texture properties and acidities of $1.0 \mathrm{Zn} / \mathrm{Z}, 2.0 \mathrm{Zn} / \mathrm{Z}$ and $3.0 \mathrm{Zn} / \mathrm{Z}$.

\begin{tabular}{|c|c|c|c|c|c|c|c|c|}
\hline \multirow{2}{*}{ Catalyst } & \multirow{2}{*}{$\begin{array}{c}\text { Zn Content }{ }^{a} \\
\text { (wt. } \%)\end{array}$} & \multirow{2}{*}{$\begin{array}{c}\mathrm{S}_{\mathrm{BET}} \mathrm{b} \\
\left(\mathrm{m}^{2} \mathrm{~g}^{-1}\right)\end{array}$} & \multirow{2}{*}{$\begin{array}{c}V_{\text {total }} \mathrm{b} \\
\left(\mathrm{cm}^{3} \mathrm{~g}^{-1}\right)\end{array}$} & \multirow{2}{*}{$\begin{array}{l}V_{\text {micro }} b \\
\left(\mathrm{~cm}^{3} \mathrm{~g}^{-1}\right)\end{array}$} & \multicolumn{4}{|c|}{ Amount of Acid Sites $\left(\mathrm{mmol} \mathrm{g}^{-1}\right)^{\mathrm{c}}$} \\
\hline & & & & & $\mathbf{W}$ & $\mathbf{M}$ & S & Total \\
\hline HZSM-5 & - & 402 & 0.34 & 0.14 & 0.83 & 0.00 & 0.31 & 1.14 \\
\hline $1.0 \mathrm{Zn} / \mathrm{Z}$ & 0.99 & 384 & 0.34 & 0.13 & 0.82 & 0.16 & 0.15 & 1.13 \\
\hline $2.0 \mathrm{Zn} / \mathrm{Z}$ & 1.70 & 372 & 0.29 & 0.12 & 0.82 & 0.23 & 0.08 & 1.13 \\
\hline $3.0 \mathrm{Zn} / \mathrm{Z}$ & 2.93 & 355 & 0.26 & 0.11 & 0.82 & 0.26 & 0.06 & 1.14 \\
\hline
\end{tabular}

${ }^{a}$ : Elemental composition measured by inductively coupled plasma optical emission spectrometry (ICP-OES); ${ }^{\text {}}: \mathrm{S}_{\mathrm{BET}}$, Brunauer-EmmettTeller (BET) surface area; $\mathrm{V}_{\text {micro }}$, micropore volume determined by $\mathrm{t}$-plot; $\mathrm{V}_{\text {total }}$, total pore volume; ${ }^{\mathrm{c}}$ : Amount of desorbed ammonia; $\mathrm{W}$, weak acidic site; $\mathrm{M}$, medium acidic site; $\mathrm{S}$, strong acidic site.

$\mathrm{N}_{2}$ adsorption-desorption isotherms were measured at $77 \mathrm{~K}$ to analyze the texture properties of the ZSM-5 samples. According to the IUPAC classification, the isotherms exhibit Type I and IV, which demonstrate the existence of micropores and mesopores as shown in Figure 1c. The fitted Brunauer-Emmett-Teller (BET) specific surface areas and pore volumes by $t$-plot method are listed in Table 1. HZSM-5, 1.0Zn/Z, 2.0Zn/Z and $3.0 \mathrm{Zn} / \mathrm{Z}$ show BET surface areas of $402,384,372$ and $355 \mathrm{~m}^{2} \mathrm{~g}^{-1}$, total pore volume of 0.34 , $0.34,0.29$ and $0.26 \mathrm{~cm}^{3} \mathrm{~g}^{-1}$, microporous volume of $0.14,0.13,0.12$ and $0.11 \mathrm{~cm}^{3} \mathrm{~g}^{-1}$. It can be seen that porosity decreases with $\mathrm{Zn}$ content increases.

Acidities are tested by $\mathrm{NH}_{3}$ temperature-programmed desorption. As shown in Figure S3, samples show weak acid desorption peaks of $240-260{ }^{\circ} \mathrm{C}$, medium-strong acid peaks of $300-350^{\circ} \mathrm{C}$ and strong acid peaks of $490-510{ }^{\circ} \mathrm{C}$. Detailed acid amount are fitted and showed in Table 1. It can be seen that amount of weak acid sites is $0.83 \mathrm{mmol} \mathrm{g}^{-1}$ for HZSM-5, and $0.82 \mathrm{mmol} \mathrm{g}^{-1}$ for three Zn-loaded samples. Medium-strong acid sites increase of $0.16 \mathrm{mmol} \mathrm{g}^{-1}$ for $1.0 \mathrm{Zn} / \mathrm{Z}, 0.23 \mathrm{mmol} \mathrm{g}^{-1}$ for $2.0 \mathrm{Zn} / \mathrm{Z}$ and $0.26 \mathrm{mmol} \mathrm{g}^{-1}$ for $3.0 \mathrm{Zn} / \mathrm{Z}$ with the increase of $\mathrm{Zn}$ content, while strong acid sites decrease of $0.31 \mathrm{mmol} \mathrm{g}^{-1}$ for HZSM-5, $0.15 \mathrm{mmol} \mathrm{g}^{-1}$ for $1.0 \mathrm{Zn} / \mathrm{Z}, 0.08 \mathrm{mmol} \mathrm{g}^{-1}$ for $2.0 \mathrm{Zn} / \mathrm{Z}$ and $0.06 \mathrm{mmol} \mathrm{g}^{-1}$ for $3.0 \mathrm{Zn} / \mathrm{Z}$. It is in accordance with reports [18] that $\mathrm{Zn}$-Lewis acid sites generate by loaded $\mathrm{Zn}$ and Brønsted acid sites.

X-ray photoelectron spectroscopy (XPS) was measured to distinguish the Zn species on the zeolite samples by the fitting of $Z n 2 p_{3 / 2}$. As shown in Figure 1d, decreased binding energy of $\mathrm{Zn} 2 p_{3 / 2}$ is observed with $\mathrm{Zn}$ content increases, which could be divided into contributions of $\mathrm{ZnO}(1022.8 \mathrm{eV})$ and $\mathrm{ZnOH}^{+}(1023.8 \mathrm{eV})$ according to previous reports [18]. As shown in Table 2, the contents of $\mathrm{ZnO}$ ratio increases from $13.9 \%(1.0 \mathrm{Zn} / \mathrm{Z})$ to $93.2 \%$ $(3.0 \mathrm{Zn} / \mathrm{Z})$, while $\mathrm{ZnOH}^{+}$decreases from $86.1 \%$ to $6.8 \%$ with $\mathrm{Zn}$ content increases. It can be seen that $\mathrm{Zn}$ species convert from ion-state to oxide with the increase in amount, which is in accordance with previous reports [21].

Table 2. Ratios of Zn species measured by fitting of XPS Zn $2 p_{3 / 2}$ peaks on $1.0 \mathrm{Zn} / \mathrm{Z}, 2.0 \mathrm{Zn} / \mathrm{Z}$ and $3.0 \mathrm{Zn} / \mathrm{Z}$ before and after reactions.

\begin{tabular}{ccccc}
\hline \multirow{2}{*}{ Catalyst } & \multicolumn{2}{c}{ Ratios of Zn Species before Reaction } & \multicolumn{2}{c}{ Ratios of Zn Species after Reaction } \\
\cline { 2 - 5 } & $\mathbf{Z n O ~ ( \% )}$ & $\mathbf{Z n O H}^{+}(\mathbf{\% )}$ & $\mathbf{Z n O ~ ( \% )}$ & $\mathbf{Z n O H}^{+} \mathbf{( \% )}$ \\
\hline $1.0 \mathrm{Zn} / \mathrm{Z}$ & 13.9 & 86.1 & 35.4 & 64.6 \\
$2.0 \mathrm{Zn} / \mathrm{Z}$ & 36.2 & 63.8 & 55.0 & 45.0 \\
$3.0 \mathrm{Zn} / \mathrm{Z}$ & 93.2 & 6.8 & 96.7 & 3.3 \\
\hline
\end{tabular}

\subsubsection{Catalysis}

Catalytic performance for methane conversion and aromatic production were evaluated. First of all, methanol conversions were $100 \%$ in MTA and co-reactions under conditions in this work. As shown in Figure 2a, HZSM-5 has little methane conversion, as low as $1.0 \%$, while $1.0 \mathrm{Zn} / \mathrm{Z}$ increases to $7.5 \%$. With further increase of $\mathrm{Zn}$ loadings, conversions decrease, where $2.0 \mathrm{Zn} / \mathrm{Z}$ has methane conversion of $6.7 \%$ and $3.0 \mathrm{Zn} / \mathrm{Z}$ below zero. It can be seen that higher $\mathrm{Zn}$ loading has strong methanol-to-methane effect, which 
is disadvantageous for methane conversion. Figure $\mathrm{S} 4$ shows the product distribution of MTA and co-reactions. Little change of product distribution by HZSM- 5 is caused after co-feed with methane, which might be attributed to the poor methane transformation. Figure $2 \mathrm{~b}$ shows the detailed difference before and after methane added. It can be seen that $1.0 \mathrm{Zn} / \mathrm{Z}$ and $2.0 \mathrm{Zn} / \mathrm{Z}$ have obvious increased high valued-added aromatics and $C_{2}$ and $C_{3}$ alkene productions, where $1.0 \mathrm{Zn} / \mathrm{Z}$ has the highest aromatics production of $52.2 \%$. Moreover, no obvious changes, nor $C_{2}$ and $C_{3}$ alkene productions improvements are obtained by $3.0 \mathrm{Zn} / \mathrm{Z}$.
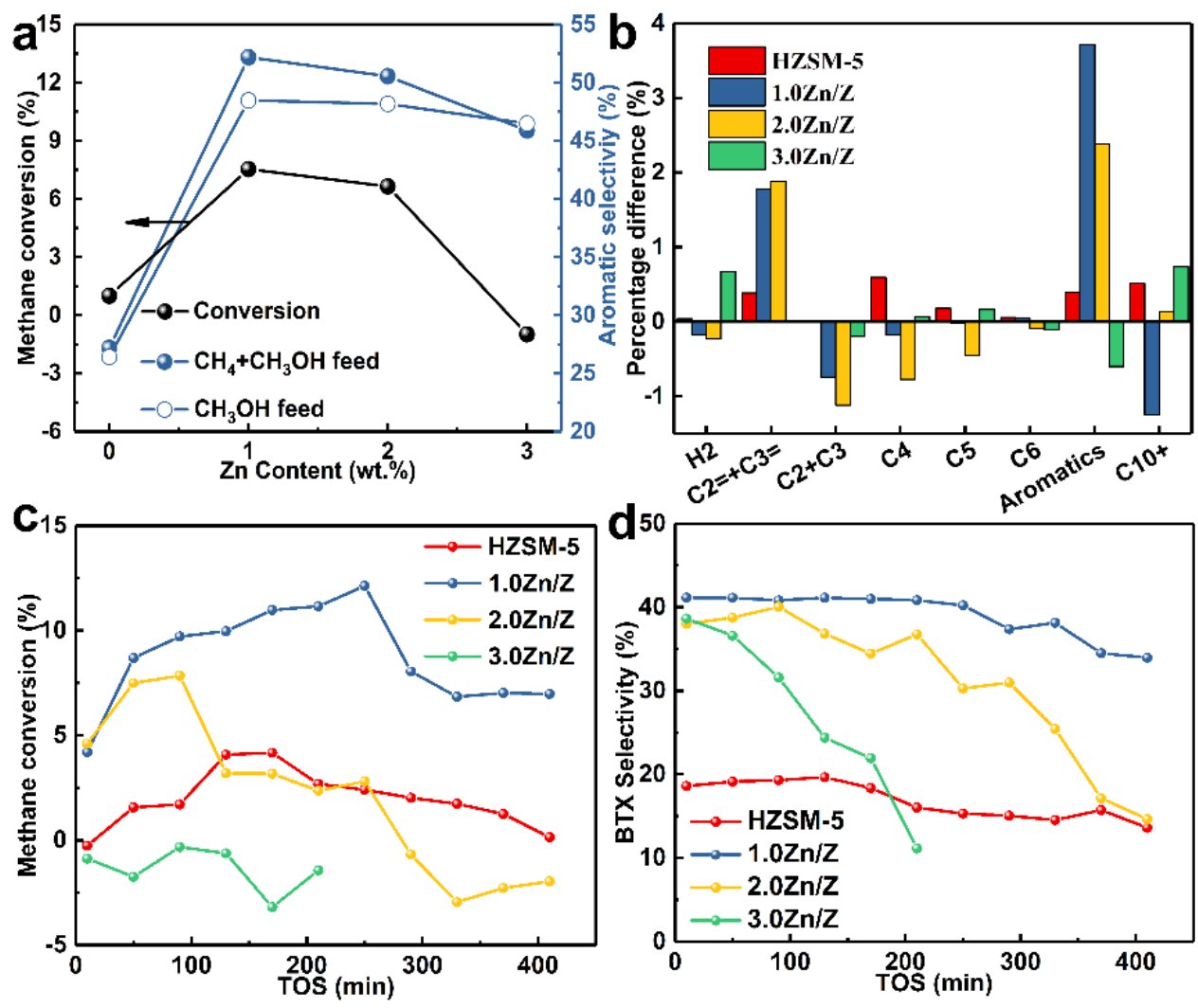

Figure 2. Methane conversion and aromatics selectivities of MTA and co-reaction over HZSM-5 and Zn-modified ZSM-5 zeolites $\left(0.67 \mathrm{~g}\right.$ catalyst, $37.1 \mathrm{~mL} \cdot \mathrm{min}^{-1} \mathrm{~N}_{2}$ flow rate in MTA reaction or $37.1 \mathrm{~mL} \cdot \mathrm{min}^{-1}$ mixed gas of $\mathrm{N}_{2}$ and $\mathrm{CH}_{4}, 0.045 \mathrm{~mL} \cdot \mathrm{min}^{-1}$ methanol flow rate, the methanol to methane molar ratio is 1.3 , average data calculated by performance at $10 \mathrm{~min}, 50 \mathrm{~min}, 90 \mathrm{~min}$ ) (a); difference of product distribution between co-reaction and MTA reaction (b); methane conversion (c) and BTX selectivity (d) of co-reaction over HZSM-5 and Zn-modified ZSM-5 zeolites with time on stream.

Figure 2c,d show the methane conversion and production distribution of MTA and co-reaction on ZSM- 5 zeolites with time on stream. It can be seen that induction periods exist at the initial stage of reaction, which is the same as previous reports [22]. HZSM-5 reaches maximum conversion of $4.2 \%$ at $170 \mathrm{~min}$, while $1.0 \mathrm{Zn} / \mathrm{Z}$ reaches $12.1 \%$ at $250 \mathrm{~min}$, and $2.0 \mathrm{Zn} / \mathrm{Z} 7.9 \%$ at $90 \mathrm{~min}$. $3.0 \mathrm{Zn} / \mathrm{Z}$ has consistent methane conversion below zero. As shown in Figure 2d, aromatic selectivities of all samples reduce with time on stream. HZSM-5 has poor selectivity below 20\%. After Zn loaded, BTX selectivities increase to $32-41 \%$ at $10 \mathrm{~min}$. It can be seen that $1.0 \mathrm{Zn} / \mathrm{Z}$ has longest service life that maintains selectivity of $34.0 \%$ at $410 \mathrm{~min}$, while selectivities by $2.0 \mathrm{Zn} / \mathrm{Z}$ and $3.0 \mathrm{Zn} / \mathrm{Z}$ have rapid decline. It can be concluded that $1.0 \mathrm{Zn} / \mathrm{Z}$ has best performance in methane conversion and BTX selectivity among these samples.

XRD was performed to distinguish the $\mathrm{Zn}$ species for further investigation of the deactivated catalysts. As shown in Figure S5, spent ZSM-5 samples maintain topology 
of MFI, which reveals good structure stability. Besides, stronger peaks of $\mathrm{ZnO}$ could be detected, which might be attributed to the aggregation of Zn. Figure 3a shows detailed peaks of $\mathrm{ZnO}$. It can be seen that peaks at $31.8^{\circ}, 34.5^{\circ}$ and $36.3^{\circ}$ move to higher degrees with $\mathrm{Zn}$ content increases. On account of the higher degrees of $\mathrm{ZnO}$, it might be caused by more aggregation of $\mathrm{ZnO}$. XPS spectra further give the state of $\mathrm{Zn}$ species. As shown in Figure $3 \mathrm{~b}$ and Table 2, binding energies of $\mathrm{Zn} 2 p_{3 / 2}$ shift lower with the increase of $\mathrm{Zn}$ capacity, which demonstrate that the amount of $\mathrm{ZnO}$ increases with the increase of $\mathrm{Zn}$ loading. Besides, higher $\mathrm{ZnO}$ content and lower $\mathrm{ZnOH}^{+}$content could be detected after reaction in all the three samples, which reveals that the deactivation might be attributed to the conversion of $\mathrm{Zn}$.
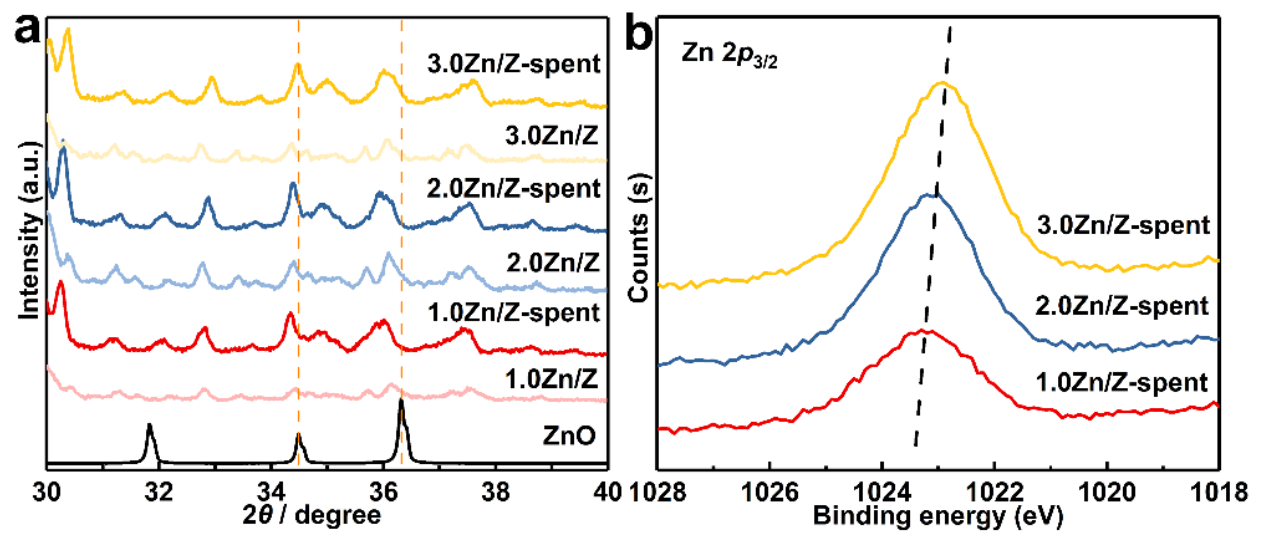

Figure 3. $X$-ray diffraction (XRD) patterns in range of $30-40^{\circ}$ (a) and XPS spectra of Zn modified ZSM-5 samples after reaction (b).

Based on above investigations, Zn substitution in zeolites present improved performance in methane conversion co-react with MTA reaction, and further present an optimized $\mathrm{Zn}$ loading of $1.0 \mathrm{wt} . \%$. On the one hand, $\mathrm{Zn}$ species promote the activation of methane. On the other hand, the increase of $Z n$ content decreases the porosity of samples, varies the acidities and the states of $\mathrm{Zn}$ species, and further change the conversion activities and serving lifetimes. In this section, an optimized $\mathrm{Zn}$ content is determined to be $1.0 \mathrm{wt} . \%$. It has maximum methane conversion of $7.9 \%$, and aromatic selectivity of $52.2 \%$, which is similar to the reported $6-8 \%$ of $5 \% \mathrm{Mo} / \mathrm{HZSM}-5$ at $550{ }^{\circ} \mathrm{C}$ [7], reported $2-4 \%$ of $4.68 \% \mathrm{Zn} / \mathrm{ZSM}-5$ at $500{ }^{\circ} \mathrm{C}$ [23], and reported $7-9 \%$ of $2-4 \% \mathrm{GaO}_{3} / \mathrm{ZSM}-5$ at $550{ }^{\circ} \mathrm{C}$ [24].

\subsection{ZSM-5 Catalysts with Different Zn Loading Strategies for Methane Conversion in Co-Reaction of MTA Reaction}

The preparation strategies of impregnation, ion exchange and physical mixing are common methods to load metal on zeolites, which cause variation of the state of $\mathrm{Zn}$. In the previous section, $\mathrm{Zn}$ content was optimized to be $1.0 \mathrm{wt} . \%$. In this section, ion exchange and physical mixing were used to prepare 1.0Zn/Z-IE and 1.0Zn/Z-PM at doping content of $1.0 \mathrm{wt} . \%$ for methane conversion with co-feeding of methanol to produce BTX as comparison to $1.0 \mathrm{Zn} / \mathrm{Z}$.

\subsubsection{Characterization}

Figure 4a shows the XRD patterns of HZSM-5, 1.0Zn/Z, 1.0Zn/Z-IE, 1.0Zn/Z-PM and MFI simulated one. It can be seen that the frameworks of $Z n$ modified catalysts maintain stable after loadings. In detailed peaks at $30-40^{\circ}$ shown in Figure $4 \mathrm{~b}$, no obvious peaks of $\mathrm{ZnO}$ for $1.0 \mathrm{Zn} / \mathrm{Z}$ and 1.0Zn/Z-IE can be detected, which indicates good dispersion of $\mathrm{Zn}$ species on the zeolites. Weak peaks at $31.8^{\circ}, 34.5^{\circ}$ and $36.3^{\circ}$ for $1.0 \mathrm{Zn} / \mathrm{Z}-\mathrm{PM}$ are observed, which indicates the existence of $\mathrm{ZnO}$ aggregated by $\mathrm{Zn}$ species. Same polyhedral morphology with diameter of $2 \mu \mathrm{m}$ could be detected in the $\mathrm{Zn}$ modified samples (Figure S1). ICP-OES spectra were performed to measure the $\mathrm{Zn}$ content. As 
shown in Table 3, 1.0Zn/Z has Zn content of 0.99 wt.\%, while $1.0 \mathrm{Zn} / \mathrm{Z}$-IE $1.11 \mathrm{wt} . \%$, and $1.0 \mathrm{Zn} / \mathrm{Z}-\mathrm{PM} 1.03 \mathrm{wt} . \%$. It can be seen that $\mathrm{Zn}$ content are as same as $1.0 \mathrm{wt} . \%$ of the three Zn-modified ZSM-5 catalysts. Besides, uniform distributions of Zn species are proved by EDS images as shown in Figure S2.
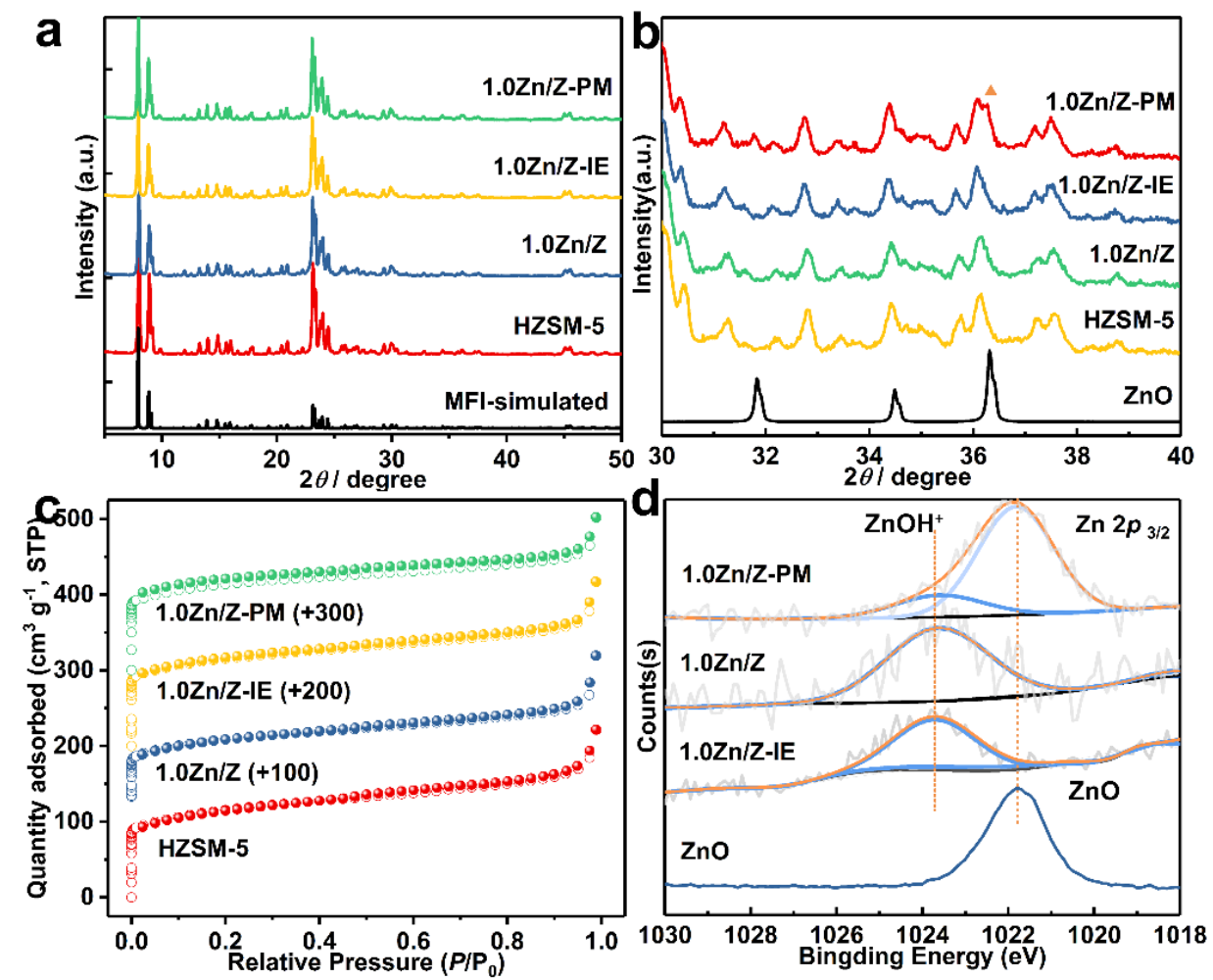

Figure 4. XRD patterns in range of $5-50^{\circ}$ of ZSM-5 samples and MFI simulated one (a), and in range of $30-40^{\circ}$ of ZSM- 5 samples and $\mathrm{ZnO}(\mathbf{b}) ; \mathrm{N}_{2}$ adsorption-desorption isotherms at $77 \mathrm{~K}$ of HZSM- 5 and ZSM-5 samples by different Zn-loading strategies (c); fittings of Zn $2 p_{3 / 2}$ peaks in XPS spectra of $\mathrm{ZnO}$ and ZSM-5 samples by different $\mathrm{Zn}$-loading strategies (d).

Table 3. Zn content, texture properties, acidities and ratios of Zn species of 1.0Zn/Z, 1.0Zn/Z-IE and 1.0Zn/Z-PM.

\begin{tabular}{|c|c|c|c|c|c|c|c|c|c|c|}
\hline \multirow[t]{2}{*}{ Catalyst } & \multirow{2}{*}{$\begin{array}{l}\text { Zn Content } \\
\quad(w t . \%)\end{array}$} & \multirow{2}{*}{$\begin{array}{c}\mathrm{S}_{\mathrm{BET}} \mathrm{b} \\
\left(\mathrm{m}^{2} \mathrm{~g}^{-1}\right)\end{array}$} & \multirow{2}{*}{$\begin{array}{c}V_{\text {total }}{ }^{b} \\
\left(\mathrm{~cm}^{3} \mathrm{~g}^{-1}\right)\end{array}$} & \multirow{2}{*}{$\begin{array}{l}V_{\text {micro }} b \\
\left(\mathrm{~cm}^{3} \mathrm{~g}^{-1}\right)\end{array}$} & \multicolumn{4}{|c|}{$\begin{array}{l}\text { Amount of Acid Sites } \\
\left(\mathrm{mmol} \mathrm{g}^{-1}\right)\end{array}$} & \multicolumn{2}{|c|}{$\begin{array}{l}\text { Ratios of Zn } \\
\text { Species d (\%) }\end{array}$} \\
\hline & & & & & $\mathbf{W}$ & $\mathbf{M}$ & S & Total & $\mathrm{ZnO}$ & $\mathrm{ZnOH}^{+}$ \\
\hline $1.0 \mathrm{Zn} / \mathrm{Z}$ & 0.99 & 384 & 0.34 & 0.13 & 0.82 & 0.09 & 0.23 & 1.14 & 13.9 & 86.1 \\
\hline $1.0 \mathrm{Zn} / \mathrm{Z}-\mathrm{IE}$ & 1.11 & 397 & 0.34 & 0.13 & 0.82 & 0.16 & 0.15 & 1.13 & 3.9 & 96.1 \\
\hline 1.0Zn/Z-PM & 1.03 & 397 & 0.34 & 0.14 & 0.82 & 0.20 & 0.12 & 1.14 & 81.9 & 19.1 \\
\hline
\end{tabular}

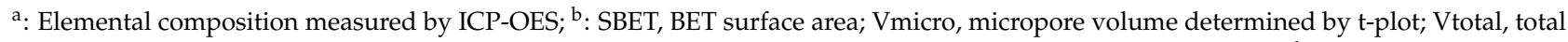
pore volume.; ${ }^{c}$ : Amount of desorbed ammonia; W, weak acidic site; M, medium acidic site; S, strong acidic site; ${ }^{\mathrm{d}}$ : Measured by XPS.

The $\mathrm{N}_{2}$ adsorption-desorption isotherms at $77 \mathrm{~K}$ are shown in Figure $4 \mathrm{c}$. All of them exhibit type I and IV isotherms according to the IUPAC classification. Table 3 shows the BET specific surface areas and pore volumes. $1.0 \mathrm{Zn} / \mathrm{Z}$ has BET specific surface area of $384 \mathrm{~m}^{2} \mathrm{~g}^{-1}$, while $1.0 \mathrm{Zn} / \mathrm{Z}$-IE $397 \mathrm{~m}^{2} \mathrm{~g}^{-1}$ and $1.0 \mathrm{Zn} / \mathrm{Z}-\mathrm{PM} 397 \mathrm{~m}^{2} \mathrm{~g}^{-1}$. Besides, all of the pore volumes of $1.0 \mathrm{Zn} / \mathrm{Z}, 1.0 \mathrm{Zn} / \mathrm{Z}$-IE and $1.0 \mathrm{Zn} / \mathrm{Z}-\mathrm{PM}$ are $0.34 \mathrm{~cm}^{3} \mathrm{~g}^{-1}$. Accordingly, the texture properties change little after metal loading.

The acid properties of ZSM-5 samples were measured by $\mathrm{NH}_{3}$-TPD. As shown in Figure S6, all of the samples exhibit a weak acid peak at $240-260^{\circ} \mathrm{C}$ and a strong acid peak at $490-510{ }^{\circ} \mathrm{C}$. After $\mathrm{Zn}$ loadings, new medium strong acid peak generates at $300-350{ }^{\circ} \mathrm{C}$. Table 3 shows the fitted amount of acid sites. It can be seen that the amount of total 
and weak acid site keeps $1.13-1.14 \mathrm{mmol} \cdot \mathrm{g}^{-1}$ and $0.82-0.83 \mathrm{mmol} \cdot \mathrm{g}^{-1}$ before and after $\mathrm{Zn}$ loading. The strong acid site transforms to medium strong ones by different loading strategies to varying degrees. Physical mixing generates the least amount of medium strong acid site of $0.09 \mathrm{mmol} \cdot \mathrm{g}^{-1}$, and keeps strong acid site amount of $0.23 \mathrm{mmol} \cdot \mathrm{g}^{-1}$. Ion exchange generates the largest amount of medium strong acid sites of $0.20 \mathrm{mmol} \cdot \mathrm{g}^{-1}$, and keeps strong acid site amount of $0.12 \mathrm{mmol} \cdot \mathrm{g}^{-1}$. Impregnation generates medium strong acid site of $0.16 \mathrm{mmol} \cdot \mathrm{g}^{-1}$, and keeps strong acid site amount of $0.15 \mathrm{mmol} \cdot \mathrm{g}^{-1}$.

The state of $\mathrm{Zn}$ species on the catalysts were further measure by XPS spectra on $\mathrm{Zn}$ $2 p_{3 / 2}$. As shown in Figure $4 \mathrm{~d}, 1.0 \mathrm{Zn} / \mathrm{Z}$ shows $\mathrm{Zn} 2 p_{3 / 2}$ at $1023.5 \mathrm{eV}, 1.0 \mathrm{Zn} / \mathrm{Z}-\mathrm{IE} 1023.8 \mathrm{eV}$ and 1.0Zn/Z-PM $1022 \mathrm{eV}$. On account of the different positions of $\mathrm{Zn}$ peaks, it can be seen that different loading strategies lead to different composition. Table 3 shows the fitted content of different states of $\mathrm{Zn}$. 1.0Zn/Z-IE shows the largest $\mathrm{ZnOH}^{+}$content of $91.6 \%$ and $\mathrm{ZnO}$ of $3.9 \%$. 1.0Zn/Z-PM shows the least $\mathrm{ZnOH}^{+}$content of $19.1 \%$ and $\mathrm{ZnO}$ of $81.9 \%$, which is in accordance with the XRD patterns. It can be seen that ion exchange generates more ion-state $\mathrm{Zn}$ species, while physical mixing generates more $\mathrm{ZnO}$.

\subsubsection{Catalysis}

Catalytic performance of Zn-loaded ZSM-5 samples for methane conversion co-feeded with methanol were tested. As shown in Figure 5 a, the catalytic activities were improved, whatever the strategy is, compared to HZSM-5 after the introduction of Zn. $1.0 \mathrm{Zn} / \mathrm{Z}$ IE shows conversion of $9.9 \%$ and selectivity of $48.8 \%$, and $1.0 \mathrm{Zn} / \mathrm{Z}-\mathrm{PM}$ shows the least conversion of $0.1 \%$ and selectivity of $42.4 \%$. Moreover, Figure S7 and Figure $5 \mathrm{~b}$ shows the product distribution and the product difference of catalysts prepared by different strategies. Compared to MTA reactions, 1.0Zn/Z-IE shows the largest aromatics improvement of $5.1 \%$, higher than $3.7 \%$ by $1.0 \mathrm{Zn} / \mathrm{Z}$ and $1.4 \%$ by $1.0 \mathrm{Zn} / \mathrm{Z}-\mathrm{PM}$. Notably, ion exchange significantly reduces the amount of $\mathrm{C} 10+$ after the addition of methane, which might be beneficial for catalyst lifetime. Therefore, ion exchange is the best for methane activation, as well as aromatics promotion. Moreover, co-reaction reduce the coke content compared to MTA reaction, especially on $1.0 \mathrm{Zn} / \mathrm{Z}$-IE.

The deactivation of catalysts prepared by different loading strategies were investigated with time on stream for the methane conversion reaction. As shown in Figure 5c, the conversion first increases and then decreases as time extends, exhibiting an induction period and deactivation. The conversion of $1.0 \mathrm{Zn} / \mathrm{Z}$-IE reaches $13.6 \%$ at $210 \mathrm{~min}$ and keeps $9.2 \%$ at $410 \mathrm{~min}$, while the conversion of $1.0 \mathrm{Zn} / \mathrm{Z}-\mathrm{PM}$ increases from $-2.2 \%$ at $10 \mathrm{~min}$ to $6.5 \%$ at $170 \mathrm{~min}$, and decreases to $4.0 \%$ at $410 \mathrm{~min}$. The BTX selectivities are further concerned. As shown in Figure S8, 1.0Zn/Z-IE has obvious higher BTX selectivity of $45.2 \%$ than $1.0 \mathrm{Zn} / \mathrm{Z}$ of $41.1 \%$, while $1.0 \mathrm{Zn} / \mathrm{Z}-\mathrm{PM}$ has lower selectivity of $37.2 \%$. It can be concluded that ion-exchange has longer serving lifetime than impregnation and ion-exchange.

Compared to HZSM-5, Zn-modification, especially for catalysts prepared by ion exchange, improves the methane activation. Moreover, ion-exchange generates more ionstate $\mathrm{Zn}$ species and medium strong acid sites than impregnation and physical mixing, which might be the key point for methane activation. Furthermore, Zn-modification is also beneficial for BTX selectivity, where high selectivity is related to high ion-state Zn species and medium strong acid sites. In addition, compared to MTA reactions, methane improves the production of high-valued BTX, especially in the ion state than oxide Zn. Therefore, the ion-state $\mathrm{Zn}$ species are active sites for methane conversion and BTX production.

To further study acid sites with different strength, the $\mathrm{NH}_{3}$-TPD curves of $1.0 \mathrm{Zn} / \mathrm{Z}$ catalysts reacted after 170 and 410 min were tested. As shown in Figure $5 \mathrm{~d}$, few strong acid sites remain after $170 \mathrm{~min}$ reaction, while methane conversion is above $11.0 \%$. The medium strong acid sites remain little after $410 \mathrm{~min}$ reaction, while methane conversion decreases to $7.0 \%$. Therefore, a strong acid site is not necessary condition for methane conversion. The methane activation might be related to medium strong acid sites, which corresponds to previous reports [14]. 

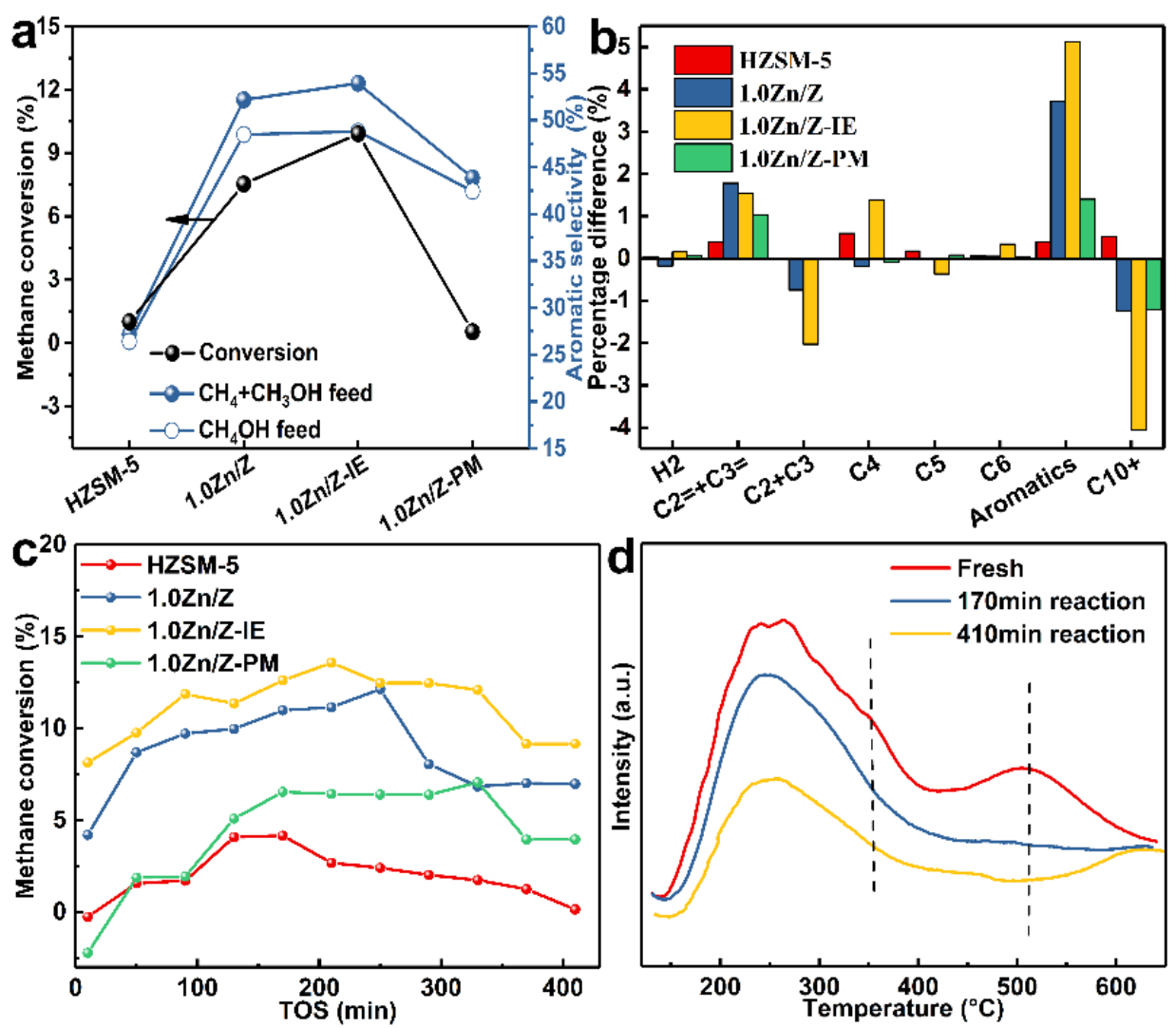

Figure 5. Methane conversion and aromatics selectivities of MTA and co-reaction over HZSM-5 and ZSM-5 samples by different Zn-loading strategies $\left(0.67 \mathrm{~g}\right.$ catalyst, $37.1 \mathrm{~mL} \cdot \mathrm{min}^{-1} \mathrm{~N}_{2}$ flow rate in MTA reaction or $37.1 \mathrm{~mL} \cdot \mathrm{min}^{-1}$ mixed gas of $\mathrm{N}_{2}$ and $\mathrm{CH}_{4}, 0.045 \mathrm{~mL} \cdot \mathrm{min}^{-1}$ methanol flow rate, the methanol to methane molar ratio is 1.3 , average data calculated by performance at $10 \mathrm{~min}, 50 \mathrm{~min}$, $90 \mathrm{~min}$ ) (a); difference of product distribution between co-reaction and MTA reaction over HZSM-5 and ZSM-5 samples by different Zn-loading strategies (b); methane conversion of co-reaction over HZSM-5 and ZSM-5 samples by different Zn-loading strategies with time on stream (c); $\mathrm{NH}_{3}$-TPD curves of $1.0 \mathrm{Zn} / \mathrm{Z}$ before reaction, after $170 \mathrm{~min}$ and $410 \mathrm{~min}$ reaction $(\mathbf{d})$.

In this section, different $\mathrm{Zn}$-loaded catalysts were prepared by impregnation, ionexchange and physical mixing. Compared to the impreganated catalyst $1.0 \mathrm{Zn} / \mathrm{Z}$, the ion-exchanged catalyst 1.0Zn/Z-IE shows larger amount of medium strong acid sites and ion-state $\mathrm{ZnOH}^{+}$content, with a similar structure, $\mathrm{Zn}$ content and texture properties. Correspondingly, 1.0Zn/Z-IE has better methane conversion activity as high as $13.6 \%$ and serving lifetime, as well as larger aromatic selectivity increase of $5.1 \%$. Oppositely, $1.0 \mathrm{Zn} / \mathrm{Z}$ $\mathrm{PM}$, prepared by physical mixing, has less medium strong acid sites, $\mathrm{ZnOH}^{+}$content, and its methane conversion activity was the worst. It can be concluded that ion-exchange is a better modification strategy for methane conversion, aromatic selectivity and serving lifetime. Besides, acidities suggested that strong acid sites are not sufficient for methane activation, while medium strong acid sites are of benefit for methane activation.

\subsection{Zn Loaded ZSM-5 Catalysts with Different Treating Atmosphere for Methane Conversion in} Co-Reaction of MTA Reaction Figures, Tables and Schemes

Based on above investigations, we aim to improve the methane conversion activity an BTX selectivity of catalysts at $1.0 \mathrm{wt} . \% \mathrm{Zn}$ capacity, and further improve the content of ion-state $\mathrm{Zn}$ species. Therefore, in this section, nitrogen and hydrogen was introduced as treating atmosphere to modify the catalyst. 


\subsubsection{Characterization}

We treated $1.0 \mathrm{Zn} / \mathrm{Z}$ catalyst by $\mathrm{H}_{2}, \mathrm{~N}_{2}$ and air. Figure $\mathrm{S} 9$ shows the $\mathrm{XRD}$ patterns of $1.0 \mathrm{Zn} / \mathrm{Z}, 1.0 \mathrm{Zn} / \mathrm{Z}-\mathrm{N}_{2}$ and $1.0 \mathrm{Zn} / \mathrm{Z}-\mathrm{H}_{2}$. Each of the patterns shows good correspondence to the MFI-simulated one. Figure 6a shows detailed peaks at range of $30-40^{\circ}$. No obvious peaks of $\mathrm{ZnO}$ are detected, which reveals good dispersion of $\mathrm{Zn}$ species in the three samples. SEM images show similar polyhedral morphology with a diameter of $2 \mu \mathrm{m}$ (Figure S1). Contents of $\mathrm{Zn}$ are measured by ICP-OES, which is $0.98 \mathrm{wt} . \%$ for $1.0 \mathrm{Zn} / \mathrm{Z}-\mathrm{H}_{2}, 1.01 \mathrm{wt} . \%$ for $1.0 \mathrm{Zn} / \mathrm{Z}-\mathrm{N}_{2}$ and $0.99 \mathrm{wt} . \%$ for $1.0 \mathrm{Zn} / \mathrm{Z}$ (Table 4). Results show that $\mathrm{Zn}$ does not run off after being calcined by a different atmosphere.
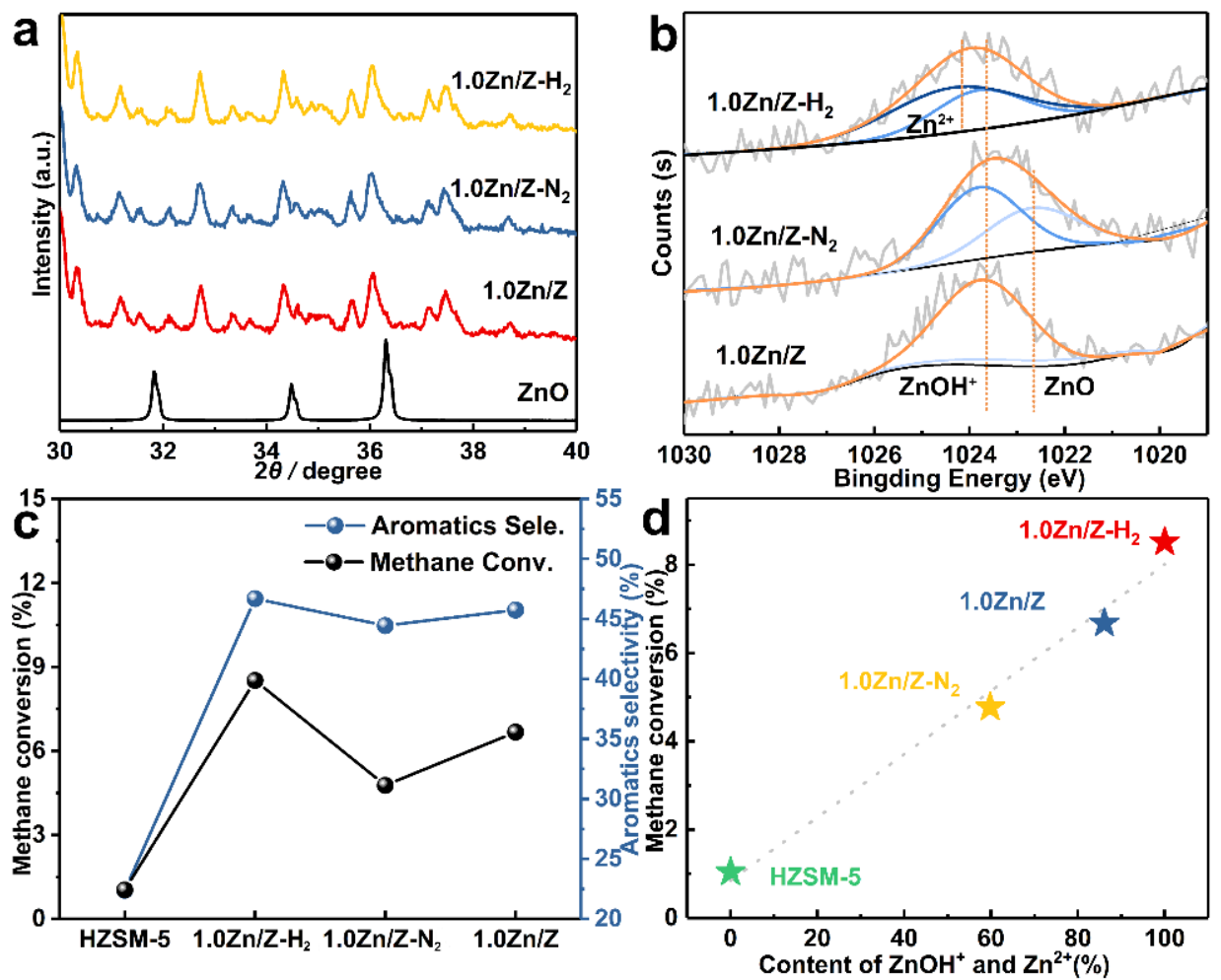

Figure 6. XRD patterns in range of 30-40 of ZSM-5 samples treated in different atmosphere and $\mathrm{ZnO}$ (a); fittings of $\mathrm{Zn} 2 p_{3 / 2}$ peaks in XPS spectra of ZnO and ZSM-5 samples treated in different atmosphere (b); methane conversion and aromatic selectivities of MTA and co-reaction over HZSM-5 and ZSM-5 samples treated in different atmosphere $\left(0.67 \mathrm{~g}\right.$ catalyst, $85 \mathrm{~mL} \cdot \mathrm{min}^{-1}$ mixed gas of $\mathrm{N}_{2}$ and $\mathrm{CH}_{4}, 0.045 \mathrm{~mL} \cdot \mathrm{min}^{-1}$ methanol flow rate, the methanol to methane molar ratio is $0.4, \mathrm{TOS}=10$, 20, $30 \mathrm{~min}$ ) (c); methane conversions with a change of ion-state $\mathrm{Zn}$ ratios by HZSM-5, 1.0Zn/Z, $1.0 \mathrm{Zn} / \mathrm{Z}-\mathrm{H}_{2}$ and $1.0 \mathrm{Zn} / \mathrm{Z}-\mathrm{N}_{2}(\mathrm{~d})$.

Table 4. Zn content of 1.0Zn/ZSM-5-25-IM catalyst calcined by different atmosphere.

\begin{tabular}{ccccc}
\hline \multirow{2}{*}{ Catalyst } & $\begin{array}{c}\text { Zn Content }^{\mathbf{a}} \\
\text { (wt.\%) }\end{array}$ & \multicolumn{3}{c}{ Ratios of Zn Species (\%) } \\
\cline { 3 - 5 } & 0.99 & $\mathbf{Z n O H}^{+}$ & $\mathbf{Z n O}$ & $\mathbf{Z n}^{2+}$ \\
\hline $1.0 \mathrm{Zn} / \mathrm{Z}$ & 0.98 & 86.1 & 13.9 & - \\
$1.0 \mathrm{Zn} / \mathrm{Z}-\mathrm{H}_{2}$ & 37.2 & - & 62.8 \\
$1.0 \mathrm{Zn} / \mathrm{Z}-\mathrm{N}_{2}$ & 1.01 & 59.8 & 40.2 & - \\
\hline
\end{tabular}

a: Elemental composition measured by ICP-OES.

The state of $Z n$ species was determined by $Z n 2 p_{3 / 2}$ peaks of XPS spectra for $1.0 \mathrm{Zn} / \mathrm{Z}$, $1.0 \mathrm{Zn} / \mathrm{Z}-\mathrm{N}_{2}$ and $1.0 \mathrm{Zn} / \mathrm{Z}-\mathrm{H}_{2}$. As shown in Figure $6 \mathrm{~b}, 1.0 \mathrm{Zn} / \mathrm{Z}-\mathrm{N}_{2}, 1.0 \mathrm{Zn} / \mathrm{Z}$ and $1.0 \mathrm{Zn} / \mathrm{Z}-$ $\mathrm{H}_{2}$ show increased binding energies, which indicates a different composition of $Z n$ species. According to previous reports [18], $\mathrm{ZnO}$ shows binding energy of $1022.8 \mathrm{eV}$ and $\mathrm{ZnOH}^{+}$of 
$1023.7 \mathrm{eV}$. Therefore, it is reasonable for the generation of $\mathrm{Zn}^{2+}$ on $1.0 \mathrm{Zn} / \mathrm{Z}-\mathrm{H}_{2}$, which is reported to show binding energy at $1024.3 \mathrm{eV}$ [20]. Table 4 shows the fitted content of $\mathrm{ZnO}$, $\mathrm{ZnOH}^{+}$and $\mathrm{Zn}^{2+}$. Compared to $1.0 \mathrm{Zn} / \mathrm{Z}, 1.0 \mathrm{Zn} / \mathrm{Z}-\mathrm{N}_{2}$ shows less $\mathrm{ZnOH}^{+}$of $59.8 \%$ and more $\mathrm{ZnO}$ of $40.2 \%$, while $1.0 \mathrm{Zn} / \mathrm{Z}-\mathrm{H}_{2}$ shows $\mathrm{ZnOH}^{+}$ratio of $37.2 \%, \mathrm{Zn}^{2+}$ ratio of $62.8 \%$, and little $\mathrm{ZnO}$ can be found. Therefore, $\mathrm{N}_{2}$ calcination promote the oxidation state of $\mathrm{Zn}$, while $\mathrm{H}_{2}$ calcination promote the ion state of $\mathrm{Zn}$, especially for $\mathrm{Zn}^{2+}$.

\subsubsection{Catalysis}

In order to reduce the interruption of methane produced by methanol-to-methane reaction, a lower ratio of $\mathrm{CH}_{3} \mathrm{OH} / \mathrm{CH}_{4}=0.4$ was performed for the investigation of $\mathrm{Zn}$ species to methane activation. Catalytic performance in co- and MTA reaction was shown in Figure 6 c. $1.0 \mathrm{Zn} / \mathrm{Z}-\mathrm{H}_{2}$ shows improved methane conversion of $8.5 \%$ and aromatic selectivity of $47.1 \%$, while $1.0 \mathrm{Zn} / \mathrm{Z}$ shows conversion of $6.7 \%$ and aromatic selectivity of $45.1 \% .1 .0 \mathrm{Zn} / \mathrm{Z}-\mathrm{N}_{2}$ has poor conversion of $4.8 \%$ and selectivity of $43.6 \%$. Figures $\mathrm{S} 10$ and $\mathrm{S} 11$ shows the product distribution and difference of catalysts calcined by a different atmosphere. Compared to MTA reactions, $1.0 \mathrm{Zn} / \mathrm{Z}-\mathrm{H}_{2}$ shows the largest aromatic improvement of $8.9 \%$, while $1.0 \mathrm{Zn} / \mathrm{Z}$ of $7.2 \%$ and $1 \mathrm{Zn} / \mathrm{Z}-\mathrm{N}_{2}$ of $6.8 \%$. It can be concluded that $1.0 \mathrm{Zn} / \mathrm{Z}-\mathrm{H}_{2}$ treated by hydrogen presents the best methane conversion activity. Besides, $1.0 \mathrm{Zn} / \mathrm{Z}-\mathrm{H}_{2}$ presents the largest promotion of aromatics and reduction of $\mathrm{C} 10+$ after methane addition.

Previous reports show that $\mathrm{ZnOH}^{+}$is an active site for methane conversion. For further study of $\mathrm{Zn}^{2+}$, the methane conversions were compared with the change of ionstate $\mathrm{Zn}$ content. As shown in Figure 6d, it can be seen that methane conversion has a positive relationship with the ion-state $\mathrm{Zn}$ content. Therefore, it is reasonable that $\mathrm{Zn}^{2+}$ is another active site for methane conversion, which is also beneficial for aromatic production.

For further comparison of $\mathrm{ZnOH}^{+}$and $\mathrm{Zn}^{2+}$, the catalytic performance of $1.0 \mathrm{Zn} / \mathrm{Z}-$ $\mathrm{IE}$ and $1.0 \mathrm{Zn} / \mathrm{Z}-\mathrm{H}_{2}$ at same reaction conditions was examined. As shown in Figure $7 \mathrm{a}$, induction period of methane conversion can be found in both of $1.0 \mathrm{Zn} / \mathrm{Z}-\mathrm{IE}$ and $1.0 \mathrm{Zn} / \mathrm{Z}$ $\mathrm{H}_{2}$ samples. Higher instantaneous conversion of $15.3 \%$ is achieved by $1.0 \mathrm{Zn} / \mathrm{Z}-\mathrm{H}_{2}$, which also maintains higher conversion of $12.0 \%$ after $410 \mathrm{~min}$ on stream. To be noted, the conversion data mentioned in this work is apparent conversion. By subtraction of methanolto-methane reaction, $1.0 \mathrm{Zn} / \mathrm{Z}-\mathrm{H}_{2}$, present conversion of $16.8 \%$, which is one of the best among similar samples in a co-reaction.
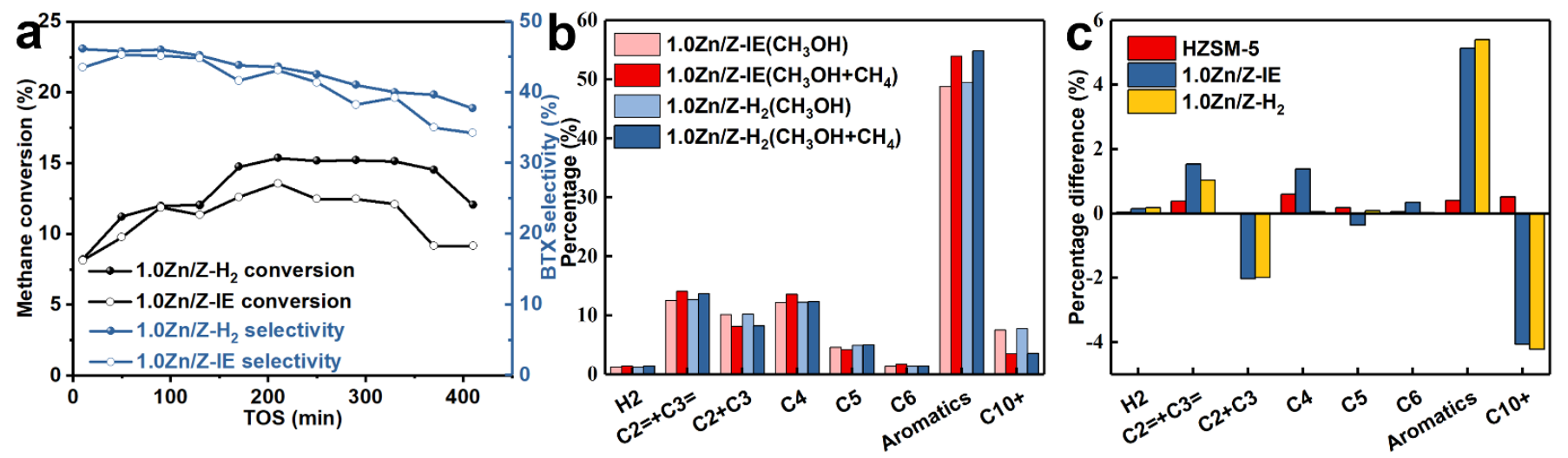

Figure 7. Methane conversions and BTX selectivities of $1.0 \mathrm{Zn} / \mathrm{Z}-\mathrm{H}_{2}$ and $1.0 \mathrm{Zn} / \mathrm{Z}$-IE with time on stream in co-reaction (a); aromatic selectivities of MTA and co-reaction over $1.0 \mathrm{Zn} / \mathrm{Z}-\mathrm{H}_{2}$ and $1.0 \mathrm{Zn} / \mathrm{Z}-\mathrm{IE}$ (b); difference of product distribution between co-reaction and MTA reaction over $1.0 \mathrm{Zn} / \mathrm{Z}-\mathrm{H}_{2}$ and $1.0 \mathrm{Zn} / \mathrm{Z}-\mathrm{IE}$ (c) $\left(0.67 \mathrm{~g}\right.$ catalyst, $37.1 \mathrm{~mL} \cdot \mathrm{min}^{-1} \mathrm{~N}_{2}$ flow rate in MTA reaction or $37.1 \mathrm{~mL} \cdot \mathrm{min}^{-1}$ mixed gas of $\mathrm{N}_{2}$ and $\mathrm{CH}_{4}, 0.045 \mathrm{~mL} \cdot \mathrm{min}^{-1}$ methanol flow rate, the methanol to methane molar ratio is 1.3 , average data calculated by performance at $10 \mathrm{~min}, 50 \mathrm{~min}, 90 \mathrm{~min}$ ).

Also, $1.0 \mathrm{Zn} / \mathrm{Z}-\mathrm{H}_{2}$ shows better performance in BTX selectivities than 1.0Zn/Z-IE. It can be seen that a maximum BTX selectivity of $46.1 \%$ is obtained. Figure $7 \mathrm{~b}$ shows the 
aromatic selectivities of MTA and co-reaction over $1.0 \mathrm{Zn} / \mathrm{Z}-\mathrm{H}_{2}$ and $1.0 \mathrm{Zn} / \mathrm{Z}$-IE. It can be seen that the addition of methane improve the aromatic selectivities on both samples. The difference of product distribution between co-reaction and MTA reaction over HZSM-5, $1.0 \mathrm{Zn} / \mathrm{Z}-\mathrm{H}_{2}$ and $1.0 \mathrm{Zn} / \mathrm{Z}$-IE is demonstrated in Figure $7 \mathrm{c}$. It can be seen that, the aromatic production increases and $\mathrm{C} 10+$ production decreases on both $\mathrm{Zn}$ loaded samples. However, there is not a big difference of production distribution between $1.0 \mathrm{Zn} / \mathrm{Z}-\mathrm{H}_{2}$ and $1.0 \mathrm{Zn} / \mathrm{Z}$-IE.

Both $1.0 \mathrm{Zn} / \mathrm{Z}-\mathrm{H}_{2}$ and $1.0 \mathrm{Zn} / \mathrm{Z}-\mathrm{IE}$ show excellent methane activations in co-reaction with MTA reaction, compared to related samples. Zn species on $1.0 \mathrm{Zn} / \mathrm{Z}-\mathrm{H}_{2}$ and $1.0 \mathrm{Zn} / \mathrm{Z}$ IE exist mainly in ion state, where $1.0 \mathrm{Zn} / \mathrm{Z}-\mathrm{H}_{2}$ has $\mathrm{Zn}^{2+}$ content of $62.8 \%$ and $\mathrm{ZnOH}^{+}$ content of $37.2 \%$, and $1.0 \mathrm{Zn} / \mathrm{Z}$-IE has $\mathrm{ZnOH}^{+}$content of $86.1 \%$. $1.0 \mathrm{Zn} / \mathrm{Z}-\mathrm{H}_{2}$ has slightly higher methane activation, and BTX selectivities than $1.0 \mathrm{Zn} / \mathrm{Z}$-IE. It seems that $\mathrm{Zn}^{2+}$ and $\mathrm{ZnOH}^{+}$are both active sites, and show similar activities in methane activation, on account of the similar performance in the $1.0 \mathrm{Zn} / \mathrm{Z}-\mathrm{H}_{2}$ and $1.0 \mathrm{Zn} / \mathrm{Z}$-IE samples.

\section{Materials and Methods}

Materials: The HZSM-5 zeolite was purchased from catalyst factory of Nankai University, whose $\mathrm{SiO}_{2} / \mathrm{Al}_{2} \mathrm{O}_{3}$ was 25 . $\mathrm{ZnO}(\mathrm{AR}), \mathrm{Zn}\left(\mathrm{NO}_{3}\right)_{2} \cdot 6 \mathrm{H}_{2} \mathrm{O}(\mathrm{AR})$ and Methanol (AR) were purchased from Sinopharm Chemical Reagents Co., Ltd.

Preparation: this work is continuation of our previous works $[9,10,14]$. In this work, the Zn-modified ZSM-5 zeolite catalysts with different Zn loadings (1.0 wt.\%, 2.0 wt.\% and $3.0 \mathrm{wt} . \%$ ) were prepared by $5 \%$ excess impregnation method detailed in previous works $[9,10]$. Zn capacities were adjusted by changing the concentration of the solution, and different amount of $\mathrm{Zn}\left(\mathrm{NO}_{3}\right)_{2} \cdot 6 \mathrm{H}_{2} \mathrm{O}$ were weighed and dissolved in deionized water in a $25 \mathrm{~mL}$ volumetric flask. All catalysts were activated in air for $3 \mathrm{~h}$ at $500{ }^{\circ} \mathrm{C}$. $\mathrm{Zn}$ modified zeolites with different loadings were named as $x \mathrm{Zn} / \mathrm{Z}(x=1.0,2.0$ and 3.0). The specific steps of the ion exchange and physical mixing used in this work were referenced in the study $[9,10]$, and the prepared catalysts were named as $1.0 \mathrm{Zn} / \mathrm{Z}$-IE and 1.0Zn/ZPM, respectively. The detailed steps of the catalysts prepared by calcination of different atmospheres were as follows: the preparation of Zn-impregnated ZSM-5 catalyst was adopted and calcined in fixed bed reactor with $90 \mathrm{~mL} \cdot \mathrm{min}^{-1} \mathrm{~N}_{2}$ or $\mathrm{H}_{2}$ for $2 \mathrm{~h}$ at $500{ }^{\circ} \mathrm{C}$. The samples were named as $1.0 \mathrm{Zn} / \mathrm{Z}-\mathrm{N}_{2}$ and $1.0 \mathrm{Zn} / \mathrm{Z}-\mathrm{H}_{2}$, respectively.

Characterization: the crystal structures of samples were characterized by X-Ray diffraction (XRD). The instrument is X'Pert PW3050/60 X-ray diffractometer produced by PANalytical Co., Ltd., and the scanning range of $2 \theta$ is $5-50^{\circ}$. The texture properties of the catalysts were measured by the $\mathrm{N}_{2}$ adsorption-desorption isotherms on Quantachrome Autosorb-iQ2 instrument produced by Quanta Company. Before the test, the sample was degassed for $12 \mathrm{~h}$ at $350{ }^{\circ} \mathrm{C}$ to remove water and impurities. The total pore specific surface area of the sample is calculated by the multi-point BET method, the micropore specific surface area and pore volume are calculated by the t-plot method. Inductively coupled plasma optical emission spectrometer (ICP-OES) is used to measure the content of elements in the sample, which is carried on an Agilent 5110 instrument. The acidic nature of the samples was characterized by $\mathrm{NH}_{3}-\mathrm{TPD}$, refer to our previous work [18] for details. The chemical valence state of zinc on the catalysts was obtained by XPS through ESCALAB 250 Xi XPS system (Thermo Fisher Scientific K-Alpha+). The excitation light source is a monochromatic $\mathrm{Al} \mathrm{K} \alpha$ micro-focus source $(1486.6 \mathrm{eV})$, the beam spot is continuously adjustable from 30-400 um, the step length is $5 \mathrm{um}$, and high-performance data acquisition $(72 \mathrm{~W})$ is realized at low power. When the analysis is being performed, The vacuum degree of system is $\leq 2 \times 10^{-7}$ mbar, scanning mode CAE. The C ( $\left.1 \mathrm{~s}\right)(284.8 \mathrm{eV})$ is used as the binding energy calibration standard to test the state of $\mathrm{Zn}$.

Catalysis: MTA reaction and methane conversion co-react with methanol feed was performed in a fix-bed reactor in this work refer to our previous works $[9,10]$. All reactions were conducted at $450{ }^{\circ} \mathrm{C}$ in usual atmospheric pressure. Molar ratio in co-reaction of $\mathrm{CH}_{3} \mathrm{OH} / \mathrm{CH}_{4}$ is 1.3 with carrier gas of nitrogen. The outlets includes $\mathrm{CH}_{4}, \mathrm{C}_{2} \mathrm{H}_{4}, \mathrm{C}_{2} \mathrm{H}_{6}$, 
$\mathrm{C}_{3} \mathrm{H}_{6}, \mathrm{C}_{3} \mathrm{H}_{8}, \mathrm{C}_{4} \sim \mathrm{C}_{10}+$ hydrocarbons (including aromatics), water, nitrogen, hydrogen and unreacted methanol or dimethyl ether, etc., and performance evaluation of catalyst and the product analysis method is detailed in the literature $[9,10]$.

The methane conversions in this article are calculated as follows (1):

$$
\mathrm{CH}_{4} \text { conversion }=100 \% \times \frac{\mathrm{CH}_{4 i n l e t} \text { wt. } \%-\mathrm{CH}_{4 o u t l e t} \text { wt. } \%}{\mathrm{CH}_{\text {4inlet }} \text { wt. } \%}
$$

It is apparent conversion including methane consumption and methanol-to-methane production.

\section{Conclusions}

The methane conversion was investigated in the co-reaction with MTA by Zn modified ZSM-5 zeolites, where Zn capacity, loading strategy, and treating atmosphere are regulated. $1.0 \mathrm{Zn} / \mathrm{Z}-\mathrm{H}_{2}$ shows the best apparent conversion up to $15.3 \%(16.8 \%$ for net conversion), and aromatic selectivity of $47.1 \%$, which is among the best compared with reported metal-modified zeolites with higher capacities. $1.0 \mathrm{wt} . \%$ was optimized capacity which is advantageous for serving lifetime, as well as methane activation and BTX selectivity. Besides, compared to MTA reaction, the addition of methane promotes the high-valued aromatic production. Ion exchange and $\mathrm{H}_{2}$ treatment significantly improve the activities of catalysts by promoting of the amount of ion-state $\mathrm{Zn}$ species, including $\mathrm{ZnOH}^{+}$and $\mathrm{Zn}^{2+}$, which are proved to be active sites for methane activation. To be noted, $\mathrm{Zn}^{2+}$ is another active site different from the reported $\mathrm{ZnOH}^{+}$. Medium strong acid sites are proved to be beneficial for methane activation, while strong acid sites are not sufficient. This work discussed the modification of Zn active site on the ZSM- 5 zeolites to prepares highly efficient catalysts for methane activation and BTX production for co-react with MTA reaction.

Supplementary Materials: The following are available online at https:/ /www.mdpi.com/article/10 $.3390 /$ catal11121540/s1, Figure S1: SEM images of HZSM-5, 1.0Zn/Z, 2.0Zn/Z, 3.0Zn/Z, 1.0Zn/Z-IE, 1.0Zn/Z-PM, 1.0Zn/Z-H2 and 1.0Zn/Z-N2, Figure S2: EDS images of HZSM-5, 1.0Zn/Z, 3.0Zn/Z, 1.0Zn/Z-IE and 1.0Zn/Z-PM, Figure S3: NH3-TPD curves of HSZM-5, 1.0Zn/Z, 2.0Zn/Z and 3.0Zn/Z, Figure S4: Product distribution of MTA and co-reactions on HSZM-5, 1.0Zn/Z, 2.0Zn/Z and 3.0Zn/Z, Figure S5: XRD patterns in range of $5-50^{\circ}$ of HSZM-5, $1.0 \mathrm{Zn} / \mathrm{Z}, 2.0 \mathrm{Zn} / \mathrm{Z}$ and $3.0 \mathrm{Zn} / \mathrm{Z}$ and MFI simulated one, Figure S6: NH3-TPD curves of HSZM-5, 1.0Zn/Z, 1.0Zn/Z-IE and 1.0Zn/ZPM, Figure S7: Product distribution of MTA and co-reactions on HSZM-5, 1.0Zn/Z, 1.0Zn/Z-IE and 1.0Zn/Z-PM, Figure S8: Aromatics selectivity of co-reaction over HSZM-5, 1.0Zn/Z, 1.0Zn/Z-IE and $1.0 Z n / Z-P M$ by different $Z n$-loading strategies with time on stream, Figure S9: XRD patterns in range of $5-50^{\circ}$ of HSZM-5, $1.0 \mathrm{Zn} / \mathrm{Z}, 1.0 \mathrm{Zn} / \mathrm{Z}-\mathrm{H} 2$ and $1.0 \mathrm{Zn} / \mathrm{Z}-\mathrm{N} 2$ and MFI simulated one, Figure S10: Product distribution of MTA and co-reactions on HSZM-5, 1.0Zn/Z, 1.0Zn/Z-H2 and 1.0Zn/Z-N2, Figure S11: Difference of product distribution between co-reaction and MTA reaction over HSZM-5, $1.0 \mathrm{Zn} / \mathrm{Z}, 1.0 \mathrm{Zn} / \mathrm{Z}-\mathrm{H}_{2}$ and $1.0 \mathrm{Zn} / \mathrm{Z}-\mathrm{N}_{2}$.

Author Contributions: Project administration, writing—review and editing, B.J.; writing—original draft preparation, Y.Y. (Yue Yu) and Z.X.; investigation and formal analysis, Y.Y. (Yue Yu) and Z.X.; data curation, Z.X. and B.Z.; funding acquisition, J.W. and Y.Y. (Yongrong Yang); supervision, Z.L., J.S., Z.H. and Y.Y. (Yao Yang). All authors have read and agreed to the published version of the manuscript.

Funding: This research was funded by the National Natural Science Foundation of China (U1663222).

Data Availability Statement: Not applicable.

Conflicts of Interest: The authors declare no conflict of interest.

\section{References}

1. Wang, Y.; Hu, P.; Yang, J.; Zhu, Y.-A.; Chen, D. C-H bond activation in light alkanes: A theoretical perspective. Chem. Soc. Rev. 2021, 50, 4299-4358. [CrossRef] 
2. Campo, P.; Martínez, C.; Corma, A. Activation and conversion of alkanes in the confined space of zeolite-type materials. Chem. Soc. Rev. 2021, 50, 8511-8595. [CrossRef]

3. Zhang, T. Recent advances in heterogeneous catalysis for the nonoxidative conversion of methane. Chem. Sci. 2021, 12, 12529-12545. [CrossRef] [PubMed]

4. Choudhary, V.R.; Kinage, A.K.; Choudhary, T.V. Low-temperature nonoxidative activation of methane over H-galloaluminosilicate (MFI) zeolite. Science 1997, 275, 1286-1288. [CrossRef]

5. Wang, A.; He, P.; Yung, M.; Zeng, H.; Qian, H.; Song, H. Catalytic co-aromatization of ethanol and methane. Appl. Catal. B-Environ. 2016, 198, 480-492. [CrossRef]

6. Wang, A.; Austin, D.; Karmakar, A.; Bernard, G.M.; Michaelis, V.K.; Yung, M.M.; Zeng, H.; Song, H. Methane upgrading of acetic acid as a model compound for a biomass-derived liquid over a modified zeolite catalyst. ACS Catal. 2017, 7, 3681-3692. [CrossRef]

7. Majhi, S.; Dalai, A.K.; Pant, K.K. Methanol assisted methane conversion for higher hydrocarbon over bifunctional Zn-modified Mo/HZSM-5 catalyst. J. Mol. Catal. A-Chem. 2015, 398, 368-375. [CrossRef]

8. Liu, Y.; Li, D.; Wang, T.; Liu, Y.; Xu, T.; Zhang, Y. Efficient conversion of methane to aromatics by coupling methylation reaction. ACS Catal. 2016, 6, 5366-5370. [CrossRef]

9. Xi, Z.; Zhou, B.; Jiang, B.; Wang, J.; Liao, Z.; Huang, Z.; Yang, Y. Efficient conversion of methane to aromatics in the presence of methanol at low temperature. Mol. Catal. 2019, 475, 110493. [CrossRef]

10. Xi, Z.; Zhou, B.; Yu, Y.; Jiang, B.; Liao, Z.; Wang, J.; Huang, Z.; Yang, Y.; Sun, J.; Yang, Y. Enhancing low-temperature methane conversion on $\mathrm{Zn} / \mathrm{ZSM}-5$ in the presence of methanol by regulating the methanol-to-aromatics reaction pathway. Catal. Sci. Technol. 2020, 10, 6161-6172. [CrossRef]

11. Gabrienko, A.A.; Lashchinskaya, Z.N.; Arzumanov, S.S.; Toktarev, A.V.; Freude, D.; Haase, J.; Stepanov, A.G. ${ }^{1}$ H MAS NMR in situ reaction monitoring reveals the particular effects of $\mathrm{Zn}^{2+}$ and $\mathrm{ZnO}$ species on the kinetics of isobutane transformation on Zn-modified zeolites. J. Phys. Chem. C 2021, 125, 21471-21480. [CrossRef]

12. Pinilla-Herrero, I.; Borfecchia, E.; Holzinger, J.; Mentzel, U.V.; Joensen, F.; Lomachenko, K.A.; Bordiga, S.; Lamberti, C.; Berlier, G.; Olsbye, U.; et al. High Zn/ Al ratios enhance dehydrogenation vs hydrogen transfer reactions of Zn-ZSM-5 catalytic systems in methanol conversion to aromatics. J. Catal. 2018, 362, 146-163. [CrossRef]

13. Conte, M.; Lopez-Sanchez, J.A.; He, Q.; Morgan, D.J.; Ryabenkova, Y.; Bartley, J.K.; Carley, A.F.; Taylor, S.H.; Kiely, C.J.; Khalid, K.; et al. Modified zeolite ZSM-5 for the methanol to aromatics reaction. Catal. Sci. Technol. 2012, 2, 105-112. [CrossRef]

14. Yu, Y.; Xi, Z.; Zhou, B.; Jiang, B.; Liao, Z.; Yang, Y.; Wang, J.; Huang, Z.; Sun, J.; Yang, Y. Acidity modification of ZSM-5 for methane conversion in co-feeding method with MTA reaction. Chem. Res. Chin. Univ. 2021. [CrossRef]

15. Tian, H.; Yang, X.; Tian, H.; Zha, F.; Guo, X.; Tang, X. Realization of rapid synthesis of H-ZSM-5 zeolite by seed-assisted method for aromatization reactions of methanol or methane. Can. J. Chem. 2021, 99, 874-880. [CrossRef]

16. Abdelsayed, V.; Smith, M.W.; Shekhawat, D. Investigation of the stability of Zn-based HZSM-5 catalysts for methane dehydroaromatization. Appl. Catal. A-Gen. 2015, 505, 365-374. [CrossRef]

17. Abdelsayed, V.; Shekhawat, D.; Smith, M.W. Effect of Fe and Zn promoters on Mo/HZSM-5 catalyst for methane dehydroaromatization. Fuel 2015, 139, 401-410. [CrossRef]

18. Niu, X.; Gao, J.; Miao, Q.; Dong, M.; Wang, G.; Fan, W.; Qin, Z.; Wang, J. Influence of preparation method on the performance of Zn-containing HZSM-5 catalysts in methanol-to-aromatics. Microporous Mesoporous Mater. 2014, 197, 252-261. [CrossRef]

19. Lashichinskaya, Z.N.; Gabrienko, A.A.; Arzumanov, S.S.; Kolganov, A.A.; Toktarev, A.V.; Freude, D.; Haase, J.; Strpanov, A.G. Which species, $\mathrm{Zn}^{2+}$ cations or $\mathrm{ZnO}$ clusters, are more efficient for olefin aromatization? ${ }^{13} \mathrm{C}$ solid-state NMR investigation of n-but-1-ene transformation on Zn-modified zeolite. ACS Catal. 2020, 10, 14224-14233. [CrossRef]

20. Gao, J.; Wie, C.; Dong, M.; Wang, G.; Li, Z.; Qin, Z.; Wang, J.; Fan, W. Evolution of Zn species on Zn/HZSM-5 catalyst under H 2 pretreated and its effect on ethylene aromatization. ChemCatChem 2019, 11, 3892-3902. [CrossRef]

21. Gao, P.; Xu, J.; Qi, G.; Wang, C.; Wang, Q.; Zhao, Y.; Zhang, Y.; Feng, N.; Zhao, X.; Li, J.; et al. Mechanistic study of methanol-toaromatics reaction over Ga-modified ZSM-5 zeolites: Understanding the dehydrogenation Process. ACS Catal. 2018, 8, 9809-9820. [CrossRef]

22. Lezcano-González, I.; Oord, R.; Rovezzi, M.; Glatzel, P.; Botchway, S.W.; Weckhuysen, B.M.; Beale, A.M. Molybdenum speciation and its impact on catalytic activity during methane dehydroaromatization in zeolite ZSM-5 as revealed by operando X-ray methods. Angew. Chem. Int. Ed. 2016, 55, 5215-5219. [CrossRef] [PubMed]

23. Wang, H.; Liu, Z.; Shen, J.; Liu, H.; Zhang, J. High-throughput screening of HZSM-5 supported metal-oxides catalysts for the coupling of methane with $\mathrm{CO}$ to benzene and naphthalene. Catal. Commun. 2005, 6, 343. [CrossRef]

24. Gim, M.Y.; Song, C.; Kim, T.H.; Song, J.H.; Kim, D.H.; Lee, K.-Y.; Song, I.K. BTX production by coaromatization of methane and propane over gallium oxide supported on mesoporous HZSM-5. Mol. Catal. 2017, 439, 134-142. [CrossRef] 